\title{
Family Friendly, Motivation Achievement and Organizational Justice: Assessing Their Effects on Innovative Behavior among Social Enterprise Employees
}

\author{
Zhihua Lianª, Lu Gao b,* \\ Xiamen University Tan Kah Kee College, Zhangzhou 363105, China \\ alawrancelian@xujc.com, bgaolu@xujc.com
}

\begin{abstract}
This paper took the social exchange and social cognitive perspectives to examine the effects of family friendly on innovative behavior for social enterprise employees, and how to play a mediation in motivation achievement and moderating effect in organizational justice. In the research, we collected 430 pairing investigation data of social enterprise employees on the 10 provinces in China for statistical analysis, and verified the data does not exist problems of common methods biases by the proposed SEM. Finally, the results indicated that family friendly has a significant positive impact on innovative behavior and motivation achievement plays a mediating role between family friendly and innovative behavior. In addition, organizational justice makes a moderated effect between motivation achievement and innovative behavior.
\end{abstract}

Keywords: Family-friendly; Motivation achievement; Organizational justice; Innovative behavior.

\section{Introduction}

A substantial current studies have linked family-friendly to favorable work outcomes, including organizational citizenship behavior (Lambert, 2000; P Wang, H Wang \& Aryee, 2013), job satisfaction (Bagger \& Li, 2014) as well as innovation (Muhammad Ali etc., 2015). For example, J Spanjol et al. (2015) has shown that employees may generate more creative behaviors when their needs of work and family life are well matched. However, these existing literatures have two limitations. Firstly, although they have explained the positive relationship between family-friendly and employee's creative behaviors, the mediation through which this relationship occurs has not been explored adequately. Lots of past surveys focused on how the external situational factors (such as person-organization fit) mediate the relationship between family-friendly policies and individual creative behaviors (J Spanjol etc., 2015). However, fewer literatures have selected intrinsic motivation (such as 'achievement motivation') as a mediator to explain this influence. Schoen et al. (2014) pointed out that individuals who are more achievement motivated exhibit greater creativity than those who are harm avoidance, which inspire us to understand that achievement motivation is well suited to be a mediator to explain the relationship between family friendly and creative behavior. Besides this, the other limitation is that we know little about what kind of circumstances will affect the relationship among family friendly, achievement motivation and creative behaviors. Beatriz et al. (2010) proved that organizational justice could provide fairer environment for employees who want to deal with uncertain work situations and then lead to more favorable behaviors. Thus, we choose organizational justice as a moderater to explain the relationship between family friendly and innovative behaviors through the mediating mechanism of achievement motivation. The goal of this article is to investigate how does family friendly lead to innovative behavior and achievement motivation mediate the effects of family friendly on individuals' innovative behavior, and we examine the moderating role of organizational justice, that is, whether the magnitude of relationship between achievement motivation and innovative behavior is different. 


\section{Literature Review and Hypotheses}

\subsection{Family-friendly and innovative behavior}

Family-friendly are broadly defined as a package of programs and arrangements designed to support employees to balance the conflicting needs of work and family life in today's fast-paced and complex environment ( Newman and Mathews,1999; Lee and Hong, 2011). These programs provide flexible work schedules, telework, child care assistance, paid leave for family care, and so on (Newman and Mathews, 1999; A L Saltzstein, Y Ting \& G H Saltzstein , 2001; Francis and Lingard , 2012). Based on social exchange theory, family-friendly policies can motivate employees to establish social exchange relationship with their organization in response to the support they received, and then lead to positive employee's behaviors (Jessica Bagger \& Andrew Li, 2014). For instance, for married men and women, family-friendly policies like 'child care assistance' and 'flexible work schedules' can help them to balance work and family commitment, and then promote their company loyalty and productivity (Saltzstein etc.,2001). Similarly, K Sahibzada et al. (2005) and Bagger et al. (2014) indicated that family-friendly programs are effective tools in reducing turnover intension and promoting job satisfaction. Actually, rich family-friendly support programs enable male and female employee to be more productive (Muhammad Ali etc., 2015) and employees may generate more creative behaviors when their individual and work environment are well matched ( $\mathrm{J}$ Spanjol etc., 2015). Thus, we suggest that employees generate greater individual creative behavior when the level of family-friendly policies is high.

H1: Family-friendly will be positivly lead to innovative behaviors.

\subsection{Mediating effects of motivation achievement}

Achievement motivation has traditionally defined as the tendency to face difficult and challenges with interest of obtaining success, enjoyment and confidence (Atkinson, 1957; Jeremy L \& Schoen, 2014). This tendency leads individuals to approach difficult and challenging tasks, exert substantial effort for performance and seek novel and creative solutions for problems (Rohit Deshpande et al., 2013). Achievement motivation is a mediating effect between the staff perception environment (Market orientation, job characteristics, Family-Friendly culture etc.) and job performance (Caldwell \& Obasi, 2010; Miksza, Tan \& Dye, 2016). For example, Karami et al. (2013) have demonstrated there was a significant relationship between organizational family-friendly support and three dimensions of achievement motivation that consists of aspiration, mastery and salience. Actually, individuals are more motivated to achieve a good performance when they feel relevant supportive care from their organization and in turn generate innovative behaviors. Expectancy theory expands on the idea of achievement motivation and has perhaps been the leading model for motivational research for the past few decades. This model demonstrates that behavior is strongly influenced by an individual's expectancy of an outcome, and the subjective value of that successful outcome. Many researchers have proven that intrinsic achievement motivation played important roles in enhancing creative behaviors (Amabile, 1996; K Leung et al., 2014). Some of them proposed that intrinsic motivation promoted employee's innovative behaviors by encouraging their curiosity in learning, willingness to take risks and persistence (Grant and Berry, 2011). Some found that individuals who are more achievement motivated exhibit greater creativity than those who are harm avoidance (Jeremy L Schoen, 2014). We believe that achievement motivation as a critical mechanism explaining the effects of family-friendly on employee's innovative behaviors; that is, family-friendly shapes innovative behaviors through achievement motivation. Therefore, we propose the following:

$\mathrm{H} 2$ : Motivation achievement mediates the effects of family-friendly on innovative behaviors.

\subsection{Moderating effects of organizational justice}

Organizational justice refers to the individual's perception, activity and action to the fairness of treatment within the organization that brings justice to the employees (Sungjoo Choi, 2011; Alamansour et al., 2012), which could be divided into three broad dimensions: separately, distributive justice, procedural justice and interactional justice (Yaser Mansour Almansour et al., 2012; Yongwon Kim et al., 2013; Vishal Gupta et al., 2014; Jiun-Lan et al., 2015). Distributive justice is the initial concept of Organizational Justice, which means the fair cognition of inputs and 
outputs (Yongwon Kim et al., 2013; Jiun-Lan HSU et al., 2015). Employees tend to compare their input and output ratios with those of others. When the ratios were balance, they can realize that reward is given fair, otherwise, they can realize the reward is given unfair (Sungjoo Choi, 2011). Procedural Justice is concerned with the perceived fairness of decision-making procedures and the enactment of those procedures (Upasana Singh et al., 2016). If employees perceive the decision making process are applied fairly, for instance, if they are allowed to take part in decision process, they will consider the decision process as accurate and unbiased (Marius van \& Dijke et al., 2012). Interactional justice indicated the importance of interpersonal behavior on employee's perception of justice. Employees expect their managers to communicate at the same level with everyone. For example, managers are required to give same and sufficient information to everyone during the announcement of decisions. Those managers who treat their subordinates unfairly or disrespect are not perceived as justice (Mücahit Çelik et al., 2012). Quite a few empirical studies have shown that organizational justice is significantly related to many work behaviors and personal outcome, such as organizational citizenship behavior(Yung-Chieh C, 2013), organizational commitment(Rashmi \& Nakra, 2014), job satisfaction(Sungjoo \& Choi, 2011), intention to stay (Constanze, Eib et al., 2015) as well as innovative behaviors. Vishal Gupta et al. (2015) found that organizational justice is positively related to employee's innovative behaviors because it enhance employee's sense of safety and trust as they begin to believe the organization will recognize their efforts and will treat them fairly even if their ideas fail. Similarly, Beatriz et al. (2010) proved the moderating effect of organizational justice on the relationship between job insecurity and its outcome, which pointed out that organizational justice can enhance employees' motivation to deal with uncertain work situations and then lead to more favorable outcomes. Therefore, organizational justice is expected to provide fair environment when employees are more motivated to engage creative behavior. Thus, the following hypothesis is developed (Figure 1).

H3: Organizational justice moderate the relationship between achievement motivation and employee's innovative behaviors.

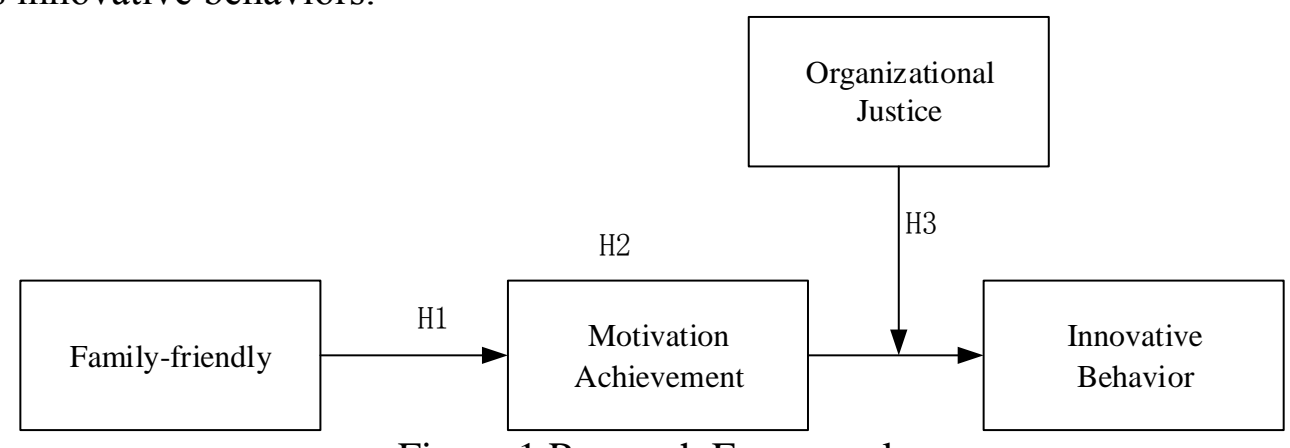

Figure 1 Research Framework

\section{Samples and procedures}

This study was conducted in the setting of social enterprise in China. We tested the proposed theoretical framework using data collected in two phases. In the first phase, all of the employees answered questions about their perception, family-friendly, motivation achievement and organizational justice. In the second phase, supervisors answered questions about the employee`s innovative behavior. We used convenience sampling and occasional sampling method and tested the hypotheses with the sample survey. Results of the descriptive analysis showed that 430 questionnaires are valid questionnaires (86 percent). All subjects who joined in this study did on a voluntary basis with ensured confidentiality. 


\section{Measurements}

\subsection{Family-friendly}

Family-friendly are employer-sponsored programs and policies that are designed to help employees manage work and personal life demands (Glass \& Finley, 2002; Lobel, 1999). The 17-item family-friendly scale(Hammer et al.,2005)was used to assess social enterprise employees family-friendly; the scale makes use of a five-point assessment system. Cronbach's $\alpha$ for this scale in the current study was 0.885 .

\subsection{Motivation Achievement}

Achievement motivation was measured by the 10-item revised Achievement Motive Scale (Lang \& Fries, 2006). Respondents are asked to respond to each subscale on a 5-point Likert-type scale ranging from (1) strongly disagree to (5) strongly agree. A sample item is worded "I enjoy situations in which I can make use of my abilities."Cronbach's $\alpha$ for this scale in the current study was 0.863 .

\subsection{Organizational Justice}

In general, organizational justice include distributive justice, interactional justice, and procedural justice. We made use of the seventeen items from Rego (2000) scale, the items being "I feel that my employer treats me fairly", "My employer's judgments are usually fair" and "I find that my employer behaves fairly towards me". The Cronbach's $\alpha$ for this scale was 0.910 .

\subsection{Innovative Behavior}

Employees' innovative behavior was measured using the six-item innovative behavior scale (Janssen O, 2008). Participants responded on a five-point Likert-type scale from 1 (not at all) to 5 (completely) to the six items. The Cronbach's $\alpha$ for this scale was 0.931 .

\section{Results and Discussion}

The descriptive statistics and intercorrelations among the variables are shown in Table 1. It summarizes the constructs and their corresponding measurement items (including sources of scale), Correlation, Composite reliability and AVE. We performed a CFA to check the reliability, validity, and uni-dimensionality of measurements used in this study. The results of CFA, as summarized in Table 1, show that the average variances extracted (AVEs) for all constructs were significantly higher than the stipulated criteria (50\%) and composite reliability values for all constructs were greater than 0.7. These figures thus demonstrated convergent validity of the measurement model. Moreover, all the inter-construct correlations in Table 1 were lower than the square root of the AVE, providing evidence of discriminant validity. Consequently, the measurement models passed both reliability and convergent/ discriminant validity checks.

Table 1. Descriptive Statistics and Correlations

\begin{tabular}{|c|c|c|c|c|c|c|c|}
\hline \multicolumn{2}{|c|}{ Construct } & \multirow{2}{*}{$\begin{array}{c}\text { Composite } \\
\text { reliability }\end{array}$} & \multirow{2}{*}{ AVE } & \multicolumn{3}{c|}{ Correlation between latent constructs } \\
\cline { 5 - 8 } & & & 1 & 2 & 3 & 4 \\
\hline 1 & Family-friendly & 0.921 & 0.520 & - & & & \\
\hline 2 & Motivation achievement & 0.900 & 0.510 & $.306^{* *}$ & - & & \\
\hline 3 & Organizational Justice & 0.926 & 0.510 & $.296^{* *}$ & $.321^{* *}$ & - & \\
\hline 4 & Innovative Behavior & 0.939 & 0.512 & $.076^{* *}$ & $.326^{* *}$ & $.178^{* *}$ & - \\
\hline
\end{tabular}

For testing the mediating and moderating effects, we followed the recommendations of Frazier, Tix, and Barron (2004). While Frazier et al. illustrated the procedure for testing mediating effects with three variables (independent variable, mediator variable, and outcome variable), we also controlled for the effect of employee's gender, age, education, tenure and marital status. As a result, we tested the hypotheses through hierarchical multiple regression. Table 2 provides the estimated parameters and results of the hypotheses testing.For $\mathrm{H} 1$, family friendly has has a significant positive effect $(\beta=.230, \rho<.001)$ on innovative behavior. Motivation achievement plays a role of mediating effect $(\mathrm{H} 2 ; \beta=.022, \rho<.05)$ between family friendly and innovative behavior. 
Table 3 show the moderating effects of organizational justice on the relationship between motivation achievement and innovative behavior. Motivation achievement has a significant positive effect $(\beta=.355, \rho<.001)$ on innovative behavior. Specifically, Tables 3 (see Model 6) show that the interactive items (Motivation achievement* Organizational Justice) were significant for innovative behavior $\mathrm{t}(\beta=.022, \rho<.05)$. This confirms that the strengthening effect of organizational justice on motivation achievement is stronger for employees with high innovative behavior (seen from Figure 2). Thus, we found support for Hypothesis 3.

Table 2. Summary of Hierarchical Regression Analysis for mediation

\begin{tabular}{|c|c|c|c|c|}
\hline \multirow{2}{*}{ Variables } & Model1 & Model2 & Model3 & Model4 \\
\hline & IB & IB & MA & IB \\
\hline Gender & $-0.108 * * *$ & $-0.083 * *$ & -0.028 & $-0.081 * *$ \\
\hline Age & -0.043 & -0.046 & $0.144 * *$ & -0.055 \\
\hline Education & $0.131 * * *$ & $0.114 * * *$ & $0.088 * *$ & $0.109 * * *$ \\
\hline Tenure & -0.007 & 0.008 & -0.020 & 0.009 \\
\hline Marital status & -0.055 & -0.031 & 0.002 & -0.031 \\
\hline FF & & $0.230 * * *$ & $0.062^{*}$ & $0.234 * * *$ \\
\hline MA & & & & $0.022 *$ \\
\hline $\mathrm{R}^{2}$ & $0.052 * * *$ & $0.108 * * *$ & $0.034 *$ & $0.111 * * *$ \\
\hline Adj-R ${ }^{2}$ & $0.047 * * *$ & $0.101 * * *$ & $0.027 *$ & $0.104 * * *$ \\
\hline $\mathrm{F}$ & $9.356^{* * *}$ & $37.003 * * *$ & $3.848^{*}$ & $26.464 * * *$ \\
\hline
\end{tabular}

Note $1: * p<.05, * * p<.01, * * * p<.001$.

Note 2: FF=Family-friendly, MA=Motivation Achievement, $\mathrm{IB}=$ Innovative Behavior.

Table 3. Summary of Hierarchical Regression Analysis for moderation

\begin{tabular}{|c|c|c|c|c|}
\hline \multirow{2}{*}{ Variables } & Model5 & \multicolumn{3}{|c|}{ Model6 } \\
\cline { 2 - 5 } & & \multicolumn{4}{|c|}{ Innovative Behavior } \\
\hline Gender & -0.024 & 0.029 & 0.028 & 0.029 \\
\hline Age & $0.154^{* * *}$ & $0.117^{* *}$ & $0.127^{* *}$ & $0.118^{* *}$ \\
\hline Education & $0.089^{* *}$ & 0.042 & 0.044 & $0.054^{*}$ \\
\hline Tenure & -0.026 & -0.018 & -0.031 & -0.015 \\
\hline Marital status & 0.008 & 0.024 & 0.023 & 0.033 \\
\hline MA & & $0.355^{* * *}$ & $0.378^{* * *}$ & $0.343^{* * *}$ \\
\hline OJ & & & $-0.072^{*}$ & $-0.086^{* *}$ \\
\hline MA*OJ & & & & $0.217^{* * *}$ \\
\hline $\mathrm{R}^{2}$ & $0.028^{* * *}$ & $0.143^{* * *}$ & $0.147^{* * *}$ & $0.192^{* * *}$ \\
\hline Adj-R & $0.028^{* * *}$ & $0.137^{* * *}$ & $0.141 * * *$ & $0.185^{* * *}$ \\
\hline $\mathrm{F}$ & $4.923^{* * *}$ & $158.953^{* * *}$ & $82.995^{* * *}$ & $80.412^{* * *}$ \\
\hline
\end{tabular}

Note $1: * p<.05, * * p<.01, * * * p<.001$.

Note 2: MA=Motivation achievement, OJ= Organizational Justice,

$\mathrm{MA} * \mathrm{OJ}=$ Motivation achievement*Organizational Justice. 


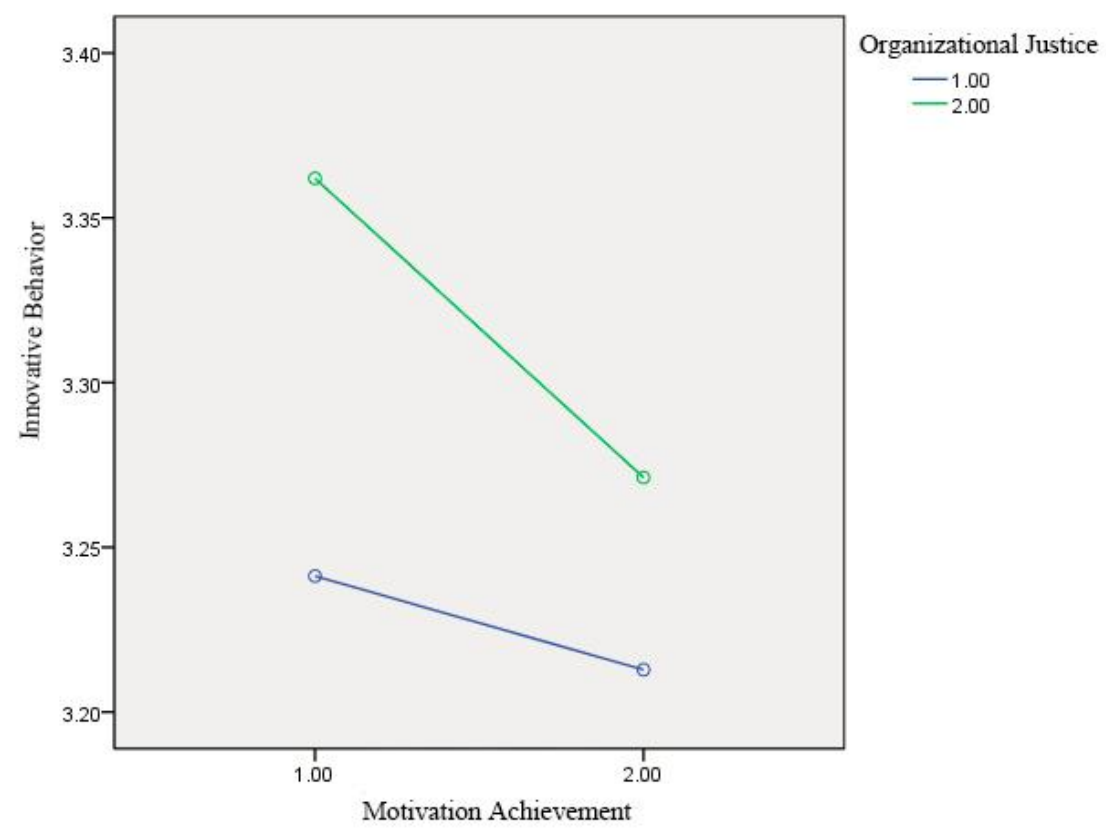

Figure 2. Moderating role of organizational justice

We tested three hypotheses. First, that family friendly would be positively associated with innovative behavior; second, that motivation achievement would be a mediating effect between family friendly and innovative behavior; and third, that organizational justice would moderate the relationship between motivation achievement and innovative behavior. Following the procedure recommended by Baron and Kenny (1986) and Ming R, W(2010), we tested the hypotheses with a sample of 430 full-time employees and 100 supervisors in Chinese. Our results support the hypothesized relationships.

\section{Research Limitations and Future Research Directions}

There are limitations to this study. First, we measured family friendly, motivation achievement, organizational justice and innovative behavior through self-reporting; thus, common method variance might have inflated the relationships between those variables. Second, our sample makes use of groups from a single industry company. Thus, the generalizability of our results needs to be tested by future replications in other service settings. We suggest that future researchers evaluate the results of this study by looking at different service settings. In addition, another direction for further research pertains to the mediating roles of psychological capital and cultural factor. Although we show that motivation achievement mediates the effect of family friendly on innovative behavior, other mediating variable may exist between family support and job behavior.

\section{Acknowledgments}

This research was supported by Humanity and Social Sciences Research Foundation of Ministry of Education of China (15YJC630069), Sciences Research Talents Project Fund for Outstanding Young Teachers in Fujian Higher Education Institutions, China(2016023). 


\section{References}

[1] M. Ali, I. Metz and C. Kulik, the Impact of Work-Family Programs on the Relationship between Gender Diversity and Performance, Human Resource Management 54 (2015), no. 4, 553-576.

[2] M. Celik and M. Sariturk, Organizational justice and motivation relationship: The case of adiyaman university, Istanbul Commerce University Journal of Social Sciences (2012), no. 21, 353-382.

[3] S. Choi, Organizational justice and employee work attitudes: The federal case, American Review of Public Administration 41 (2011), no. 2, 185-204.

[4] J. Greenberg, a Taxonomy of organizational justice theories, Academy of Management Review 12 (1987), no. 1, 9-22.

[5] Y. Guan, P. Jiang, Z. Wang, Z. Mo and F. Zhu, Self-Referent and Other-Referent career successes, career satisfaction, and turnover intention among chinese employees: The role of achievement motivation, Journal of Career Development (2016), no. 7, 1-15.

[6] V. Gupta and S. Singh, Leadership and creative performance behaviors in $r \& d$ laboratories examining the mediating role of justice perceptions, ournal of Leadership \& Organizational Studies (2015), no. 22, 21-36.

[7] J. W. B. Lang and S. Fries, A revised 10-item version of the Achievement Motives Scale: Psychometric properties in German-speaking samples, European Journal of Psychological Assessment (2006), no. 22, 216-224.

[8] Z. H. Lian and B. Wang, "Family-friendly, role stress and innovation behavior: Assessing their effects on social enterprise employee base on market orientation," International Conference on Engineering Management and Industrial Engineering, EMIE 2014, Xiamen, China, 2014, pp. 217-220.

[9] P. Miksza, L. Tan and C. Dye, Achievement motivation for band: A cross-cultural examination of the $2 \times 2$ achievement goal motivation framework, Psychology of Music (2016).1-17.

[10]J. Schoen, Effects of implicit achievement motivation, expected evaluations, and domain knowledge on creative performance, Journal of Organizational Behavior 36 (2014), no. 3, 319-338.

[11]L. Zhi-hua and Z. Ling, Supervisor support,job stress and emplyees` innovative behavior, Modern Finance (2016), no. 8, 91-101. 